Vomiting of either bile or food occurred, but except for one patient after PGVP, was not severe. Postprandial fullness after PGV has been noticed by others, ${ }^{7}: 2$ the incidence in these reports being similar to our figure of $23^{\circ}{ }_{0}$. Other symptoms such as nausea, flatulence, epigastric pain, and heartburn caused few problems. One patient reported serious degrees of all four symptoms after PGV but no physical cause could be found. Dysphagia has also been reported to be troublesome after PGV. With the exception of the patient mentioned above, in which it occurred two years after operation, it posed no great problem and was only recorded in one patient to a mild degree after PGV.

When considering the overall result by means of the Visick grading, it is perhaps disappointing to find that only $39\left(78^{\circ}{ }_{0}\right)$ and $36\left(77^{\circ}{ }_{0}\right)$ patients had a grade I or II result after PGV and PGVP respectively. A further seven $\left(14^{\circ}{ }_{0}\right)$ and two $\left(4^{\circ}{ }_{0}\right)$ patients respectively had symptoms sufficient to remove them to grade III, but still with a satisfactory result. Beyond this, the grade IV results are due to recurrence after PGV and dumping or recurrence after PGVP. The single patient with a grade III unsatisfactory result after PGV was the same man who had severe symptoms without demonstrable physical cause; after PGVP such a result was due to dumping.

PGV itself can cure duodenal ulcers without imposing serious side effects such as diarrhoea, dumping, or vomiting. When combined with pyloroplasty the number of patients with dumping increases dramatically, and since there is no other advantage to the addition of gastric drainage it should not be combined with PGV. The problem of recurrent or persistent ulcers remains. Whatever the circumstances, some recurrent ulcers probably will occur, and the number may well be equal to or slightly above those occurring after either truncal or selective vagotomy and gastric drainage. Recurrent ulcers may be treated both medically and surgically, however, whereas dumping, diarrhoea, and vomiting usually cannot, and this is the most cogent argument in favour of PGV.
We should like to thank all those who have referred patients to us; Mrs J A G Goodwin for performing the statistical analyses; and Mrs A Johnston for typing the script. All the insulin and pentagastrin tests were performed by the late J I MacNaughton.

\section{References}

1 Wastell, C, et al, British Medical fournal, 1972, 1, 28

2 Goligher, J L, British fournal of Surgery, 1974, 61, 337.

${ }^{3}$ Wastell, C, Wilson, T, and Pigott, H, Proceedings of the Royal Society of Medicine, 1974, 67, 1183.

4 Wastell, C, Annals of the Royal College of Surgeons, 1969, 45, 193.

- Grassi, G, et al, Surgery, Gynecology and Obstetrics, 1973, 136, 726.

' Liedberg, G, and Oscarson, J, Scandinavian fournal of Gastroenterology, 1973, 8 (suppl 20), 12.

' Amdrup, E, et al, Annals of Surgery, 1974, 180, 279.

${ }^{8}$ Kronborg, O, and Madsen, P, Gut, 1975, 16, 268.

${ }^{9}$ Jordan, P, Archives of Surgery, 1976, 111, 370.

${ }^{10}$ Grassi, G, in Surgery of the Stomach and Duodenum, 3rd edn. Boston, Little, Brown, (in press).

${ }^{11}$ Lyndon, P J, Johnston, D, and Greenall, M J, Gut, 1975, 16, 829.

${ }^{12}$ Hallenbeck, G A, et al, Annals of Surgery, 1976, 184, 435.

${ }^{13}$ Joergensen, P M, Holst-Christensen, J, and Kronborg, O, British fournal of Surgery, 1977, 64, 44

${ }^{14}$ Holst-Christensen, J, et al, British fournal of Surgery, 1977, 64, 42.

${ }^{15}$ Hood, J M, Spencer, E F A, and Macrae, K D, British fournal of Surgery, 1975, 62, 665

${ }^{16}$ Robbs, J V, Bank, S, and Marks, I N, British fournal of Surgery, 1973, 60, 601 .

${ }^{17}$ Kronborg, O, Gut, 1974, 15, 714.

${ }^{18}$ Kronborg, O, and Madsen, R, Scandinavian fournal of Gastroenterology, $1976,11,465$

19 Cox, A G, Spencer, J, and Tinker, J, in After Vagotomy. London, Butterworths, 1969.

${ }^{20}$ O'Leary, J P, et al, Annals of Surgery, 1976, 183, 613.

${ }^{21}$ Nelson, P G, Medical Fournal of Australia, 1968, 2, 522.

${ }^{22}$ Kennedy, T, et al, British Medical fournal, 1975, 2, 301

${ }^{23}$ Holle, F, et al, Langenbecks Archiv für klinische Chirugie, vereinigt mit Deutsche Zeitschrift für Chirurgie, 1972, 330, 197.

(Accepted 12 August 1977)

\title{
Maternal drug histories and congenital abnormalities
}

\author{
G GREENBERG，W H W INMAN，J A C WEATHERALL， A M ADELSTEIN，J C HASKEY
}

British Medical fournal, 1977, 2, 853-856

\section{Summary}

We obtained drug histories for the first trimester of pregnancy for 836 mothers of congenitally malformed babies and for an equal number of control mothers of normal babies from the same doctors' practices. There was an association between the use of a hormonal pregnancy test and the subsequent birth of a malformed

\footnotetext{
Medicines Division, Department of Health and Social Security, London EC2A 1PP

G GREENBERG, BSC, $M B$, senior medical officer

W $H$ W INMAN, MRCP, MFCM, principal medical officer
}

Medical Statistics Division, Office of Population Censuses and Surveys, London WC2B 6JP

J A C WEATHERALL, MB, MFCM, senior medical statistician

A M ADELSTEIN, FRCP, FFCM, chief medical statistician

J C HASKEY, MSC, statistician baby. There was also a greater use of barbiturates by mothers of affected children compared with mothers of control babies, mainly accounted for by treatment of epileptic mothers with phenobarbitone. For all other drugs usage was similar in both sets of mothers.

\section{Introduction}

When in 1964 a Register of Adverse Reactions was established by the Committee on Safety of Drugs, based on the voluntary reporting of suspected adverse drug reactions, particular importance was attached to identification of possible teratogens. Although about 13000 babies with visible malformations are born each year in England and Wales, only about 50 reports linking abnormalities with maternal use of drugs have been sent annually to the Committee on Safety of Medicines (CSM). Since so few reports were received it seemed likely that teratogenic effects would be missed, and a new method of surveillance was planned. The Office of Population Censuses and Surveys (OPCS) co-operated in a pilot study carried out in 1969, which showed the feasibility of a case-control survey. The major survey began in 1972 . 
In April 1975 we reported a possible association between congenital malformations and the use of hormonal pregnancy tests seen in the first 149 case-control pairs in our series. ${ }^{1}$ We now report on data obtained in the larger series, which support this association.

\section{Patients and methods}

The doctor, midwife, or health visitor attending the birth of an abnormal baby may report the abnormality to the area health authority. This information is then passed to the OPCS. Though voluntary, we believe that notification of visible and severe malformations is reasonably complete.

When the study was planned we hoped to investigate all cases of oral cleft (hare lip or cleft palate) and a $5 \%$ random sample of babies with other abnormalities. We did not, however, achieve this target, so we had to reduce the number of cases of oral cleft studied and eliminate all minor malformations included in the original $5^{\circ}$ sample. The distribution of types of abnormality in our study groups does not therefore resemble that in the total population of abnormal births.

Medical officers of health or community physicians were asked to identify the baby and provide the name and address of the general practitioner, who was then (if willing to participate) interviewed by one of the Committee's medical field workers. Details were obtained about the antenatal, personal, and family history and drugs prescribed during the first trimester.

Similar information was obtained at the same interview about the mother of a "control" baby, defined as a normal baby born in the same practice within three months of the date of birth of the abnormal baby. This selection procedure for controls ensured that any change in the doctor's prescribing habit resulting from the birth of an abnormal baby in his practice was unlikely to have influenced his choice of treatment for the mother of the control child. Information provided from memory was recorded separately from that obtained from written notes, and was not used in this analysis. Interviews could not be conducted without participants knowing whether they were discussing a case or control: instructions were given to field workers to begin alternate interviews with the discussion of a control baby to reduce the tendency to concentrate the attention on case children.

The OPCS sent 2867 notifications of abnormal births to the CSM. Of these 1462 were not followed up: preliminary enquiries showed that 77 were normal babies; 292 had minor abnormalities; in 145 cases no field worker was available; and 948 cases of oral cleft were not followed up because resources were limited. This left 1405 cases for which investigation was attempted. Of these attempts, 479 were unsuccessful:

TABLE I-Birth dates of study babies

\begin{tabular}{|c|c|c|c|c|}
\hline \multirow{2}{*}{ Year } & \multicolumn{2}{|c|}{ Cases } & \multicolumn{2}{|c|}{ Controls } \\
\hline & No & ". & No & $" \circ$ \\
\hline $\begin{array}{l}1969 \\
1970 \\
1971 \\
1972 \\
1973 \\
1974\end{array}$ & $\begin{array}{r}89 \\
1 \\
470 \\
275 \\
1\end{array}$ & $\begin{array}{r}11 \\
<1 \\
56 \\
33 \\
<1\end{array}$ & $\begin{array}{r}88 \\
2 \\
16 \\
449 \\
273 \\
8\end{array}$ & $\begin{array}{r}11 \\
<1 \\
2 \\
54 \\
33 \\
<1\end{array}$ \\
\hline Total & 836 & 100 & 836 & 100 \\
\hline
\end{tabular}

in 120 the control was incorrectly selected; in 130 the doctor could not be traced; in 46 the doctor had no record; in 53 he could not cooperate; and the remaining 130 failed for various reasons such as difficulty in identifying the child from the records.

There remained 926 pairs successfully followed up. Ninety of these were subsequently excluded because the abnormality proved to be minor, leaving a total of 836 pairs on which this paper is based. Seven hundred and forty-five study babies were born in 1972 and 1973; 89 study babies $\left(11^{\circ}\right)$ ) were born in 1969 and investigated during the pilot survey (table I).

\section{Results}

AGE AND PARITY OF MOTHERS

The mean age of mothers of malformed children was 26.5 years (range 16-51) and of control mothers 26.6 years (range 16-43). One hundred and eleven mothers of abnormal babies $(13 \%)$ and 97 control mothers $\left(12^{\circ}\right)$ had a past history of miscarriage. One hundred and twenty-one case families $\left(14^{\circ}{ }_{0}\right)$ and 23 control families $\left(3^{\circ}\right)$ had a history of congenital malformations occurring in either siblings of the study baby or in other close relatives (grandparents, parents, uncles, aunts, and first cousins). The total number of births to mothers of affected babies was 1823 and to control mothers 1804 (average $2 \cdot 18$ and $2 \cdot 16$, respectively). The average number of previous pregnancies was $1 \cdot 17$ for mothers of affected babies and $1 \cdot 15$ for control mothers Eight of the former and six of the latter had had previous twin pregnancies. Eleven of the children with abnormalities were members of twin pairs. Eight of their co-twins were normal and three were abnormal. Of the three pairs of abnormal twins, an anencephalic twin to one case baby and a twin with hypospadias to another case baby were not included in this study because they were not the baby described in the notification form. One pair of conjoined twins was included as a single case, each member of the pair having a hare lip. Each abnormal twin was matched with a single control. Table II shows some of these data and summarises characteristics of mothers of case babies exposed to certain groups of drugs during the first trimester.

\section{TYPE OF ABNORMALITY}

Distribution of malformations is shown in table III. Each baby appears only once in this table, in the first appropriate category reading from above-for example, if a child had spina bifida and a cleft palate it appears only in the category of neural tube defects. Only these three categories (neural tube defects, oral clefts, and limb malformations), which included 50 or more babies, were analysed in detail.

DRUGS PRESCRIBED DURING FIRST TRIMESTER

The number of prescriptions for mothers of case babies during the first trimester was similar to that for control mothers (2094 and 2025, respectively). Medicines containing 331 different active ingredients had been prescribed. For four groups of drugs-hormonal pregnancy tests (HPT), benzodiazepines, antibiotics, and barbiturates-there was a notable difference between case and control usage (table IV) Significantly more mothers of malformed babies had used HPT. Considering only discordant pairs, the ratio of case to control exposure

TABLE II-Characteristics of mothers of case and control babies, including details of drugs used by case mothers in first trimester and numbers ( $\%$ ) of mothers with past history of miscarriage or personal or family history of congenitally abnormal births

\begin{tabular}{|c|c|c|c|c|c|c|}
\hline \multirow{2}{*}{ Characteristic } & \multicolumn{4}{|c|}{ Drugs used } & \multirow{2}{*}{ All cases } & \multirow{2}{*}{ All controls } \\
\hline & HPT & Benzodiazepines & Antibiotics & Barbiturates & & \\
\hline $\begin{array}{l}\text { Age range (years) } \\
\text { Average age (years) } \\
\text { Past history ( }(0) \text { : } \\
\text { Miscarriage } \\
\text { Congenital abnormality } \\
\text { Total births* } \\
\text { Average No of births } \\
\text { No of mothers in group }\end{array}$ & $\begin{array}{c}16-41 \\
25 \cdot 4 \\
11(12) \\
9(10) \\
237 \\
2.55 \\
93\end{array}$ & $\begin{array}{l}17-51 \\
29 \cdot 7 \\
\\
5(14) \\
7(19) \\
83 \\
2 \cdot 31 \\
36\end{array}$ & $\begin{array}{l}17-38 \\
24 \cdot 6 \\
7(11) \\
6(10) \\
130 \\
2 \cdot 09 \\
62\end{array}$ & $\begin{array}{l}16-39 \\
27 \cdot 8 \\
7(25) \\
3(11) \\
81 \\
2 \cdot 89 \\
28\end{array}$ & $\begin{array}{c}16-51 \\
26 \cdot 5 \\
111(13) \\
121(14) \\
1823 \\
2 \cdot 18 \\
836\end{array}$ & $\begin{array}{l}16-43 \\
26 \cdot 6 \\
\\
97(12) \\
23(3) \\
1804 \\
2 \cdot 16 \\
836\end{array}$ \\
\hline
\end{tabular}

*Differs from total No of pregnancies because of some twin births.
HPT $=$ Hormonal pregnancy test. 
was $2.09(\mathbf{P}<0.01)$. Fewer case and control babies had been exposed to benzodiazepines (ratio for discordant pairs 1.57) and barbiturates (ratio for discordant pairs $2 \cdot 25$ ).

TABLE III-Distribution of types of malformation among case babies. Categories are mutually exclusioe

\begin{tabular}{|c|c|c|c|c|c|}
\hline \multirow{2}{*}{\multicolumn{4}{|c|}{ Malformations }} & \multicolumn{2}{|c|}{ Affected babies } \\
\hline & & & & \multirow{2}{*}{$\begin{array}{r}\text { No } \\
189 \\
412 \\
59 \\
176\end{array}$} & $\begin{array}{l}\text { ". } \\
23 \\
49\end{array}$ \\
\hline $\begin{array}{l}\text { Neural tube defects } \\
\text { Oral clefts } \\
\text { Limb malformations } \\
\text { Other abnormalities }\end{array}$ & $\begin{array}{l}\cdots \\
\cdots \\
\cdots\end{array}$ & $\begin{array}{l}\cdots \\
\cdots \\
\cdots\end{array}$ & $\begin{array}{l}\cdots \\
\cdots \\
\cdots \\
\cdots\end{array}$ & & $\begin{array}{r}23 \\
49 \\
7 \\
21\end{array}$ \\
\hline \multicolumn{4}{|c|}{ Total } & 836 & 100 \\
\hline
\end{tabular}

TABLE IV-Drug usage among mothers of case and control babies in first trimester

\begin{tabular}{l|c|c|c|c|c|c}
\hline \multicolumn{1}{c|}{ Class of drug } & $\begin{array}{c}\text { Case } \\
\text { and } \\
\text { control }\end{array}$ & $\begin{array}{c}\text { Case } \\
\text { only }\end{array}$ & $\begin{array}{c}\text { Control } \\
\text { only }\end{array}$ & Neither & Total & $\begin{array}{c}\text { Ratio } \\
\text { case:control } \\
\text { (discordant } \\
\text { pairs) }\end{array}$ \\
\hline $\begin{array}{l}\text { Hormonal pregnancy test } \\
\text { Benzodiazepines }\end{array}$ & 20 & 73 & 35 & 708 & 836 & $2 \cdot 09^{* *}$ \\
Antibiotics \\
Barbiturates
\end{tabular}

$* * \mathrm{P}<0.01 ; \%^{2}-5.03$

$* \mathrm{P}<0.05 ; \%=12 \cdot 68$

NS - Not significant.

Table $\mathrm{V}$ shows drug usage among mothers of case and control babies after all case-control pairs who had a family history of congenital malformation in either or both families of the pair had been excluded to remove this possible confounding influence. The ratio for discordant pairs falls for each drug; the excess use of HPT by case mothers remains statistically significant $(\mathbf{P}<0 \cdot(01)$ but the excess use of barbiturates does not.

TABLE V-Drug usage in first trimester, excluding any family with a history of congenital malformation

\begin{tabular}{l|c|c|c|c|c|c}
\hline \multicolumn{1}{c|}{ Class of drug } & $\begin{array}{c}\text { Case } \\
\text { and } \\
\text { control }\end{array}$ & $\begin{array}{c}\text { Case } \\
\text { only }\end{array}$ & $\begin{array}{c}\text { Control } \\
\text { only }\end{array}$ & Neither & Total & $\begin{array}{c}\text { Ratio } \\
\text { case :control } \\
\text { use } \\
\text { (discordant } \\
\text { pairs) }\end{array}$ \\
\hline HPT & 17 & 67 & 35 & 708 & 827 & $1.91 * *$ \\
Benzodiazepines & 3 & 26 & 21 & 779 & 829 & 1.24 NS \\
Antibiotics \\
Barbiturates & 2 & 54 & 39 & 732 & 827 & 1.38 NS \\
\hline
\end{tabular}

$* * \mathrm{P}<0 \cdot 01 ; y^{2}=9 \cdot 42$

S Not significant.

Fifteen mothers of abnormal babies and three control mothers were epileptic (table VI). One epileptic mother had received no anticonvulsants during pregnancy. Eleven of the 14 treated mothers of abnormal children and one of the three control mothers had received phenobarbitone alone or in combination with one or more anticonvulsant

No other drug or groups of drugs showed an appreciable difference in usage between cases and controls (table VII). More control mothers than mothers of affected babies had used iron, with or without folic acid, but the difference was not significant. An antiemetic had been prescribed for 178 control mothers and 157 mothers of affected babies; this difference was not significant. There was a moderate though not significant excess of prescriptions for progestogen used to maintain pregnancy in mothers of affected babies ( 19 compared with 12 controls), and 11 mothers of abnormal babies and ten control mothers became pregnant while taking oral contraceptives. Thirty case and 32 control mothers had used oral contraceptives during the three months before conception.

The distribution of malformations in babies born to users of the four main drug groups is shown in table VIII. The number of babies
TABLE VI-Usage of anticonvulsants among epileptic mothers of case and control children

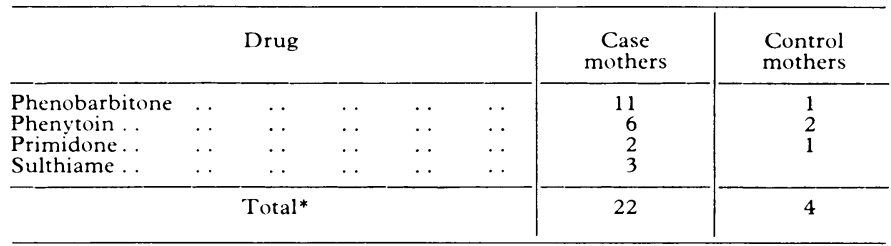

*Totals exceed the numbers of epileptic mothers on anticonvulsants because seven case mothers and one control mother were taking more than one anticonvulsant multanecusly.

TABLE VII-Other principal drugs prescribed for mothers of case and control babies in first trimester

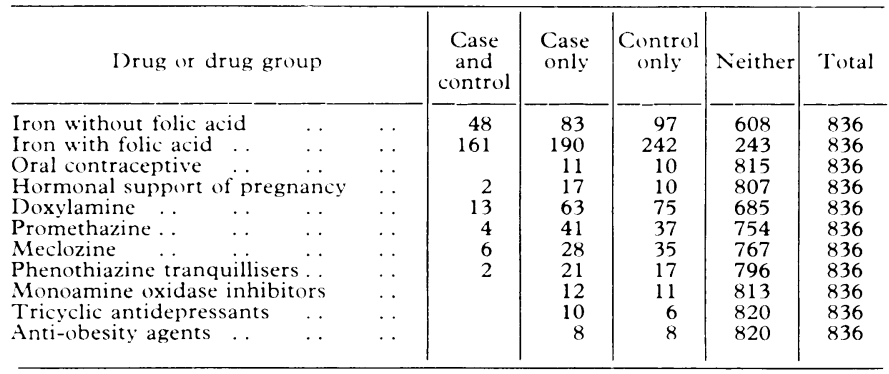

with each type of abnormality does not correspond to that shown in table III because some mothers used more than one drug. Each baby appears under one category only. For example, column five shows 14 babies with oral cleft exposed to barbiturates. In fact 17 babies so exposed had oral cleft but three of these also had neural tube defects and are therefore shown only under this category. The distribution of malformations was remarkably consistent within the drug groups, suggesting that any possible teratogenic effect was probably nonspecific.

\section{Discussion}

Ideally the mothers of abnormal babies and of control babies should have been matched in all respects, so that, age, parity, obstetric and family history, and date of birth of the babies would be identical. Birth date of babies was selected as the most important matching factor because of the possibility that the birth of an abnormal baby might affect the doctor's prescribing practice ; it was therefore essential to ensure that every control mother had completed the first trimester of her pregnancy before the abnormal birth had occurred. This was achieved by accepting as controls only babies born within three months of the case baby. This matching having been achieved, we could not match for other factors such as maternal age and parity because the number of potential controls in a single practice was usually too small. Field workers were instructed that once a suitable control baby had been selected it should on no account be rejected if, for example, the mother had suffered from some condition such as rubella or came from a family with a history of congenital abnormalities.

Cases and controls were matched closely for all factors except history of previous children with abnormalities in the study families (see table II). Furthermore, the proportion of mothers of case babies with such a history is uniformly higher in the individual treatment groups shown in table II, as well as in the group of "all cases," than in the controls. Clearly this could be an important confounding factor. A separate analysis, excluding mothers with a personal or family history of abnormality, shows that this cannot account for the effect associated with HPT, but could account for differences associated with other drug groups (table V). Nine of the 93 mothers of abnormal babies who had 
TABLE VIII-Number $\left({ }^{\circ}\right)$ of malformed babies born to mothers who had used specific drugs during first trimester, according to type of malformation. Categories are mutually exclusive*

\begin{tabular}{|c|c|c|c|c|c|c|c|c|}
\hline \multicolumn{5}{|c|}{ Malformation } & Hormonal pregnancy test & Benzodiazepines & Antibiotics & Barbiturates \\
\hline $\begin{array}{l}\text { Neural tube defects } \\
\text { Oral clefts } \\
\text { Limb malformations } \\
\text { Other } \quad . .\end{array}$ & $\begin{array}{l}\cdots \\
\cdots \\
\cdots \\
\end{array}$ & $\begin{array}{l}\cdots \\
\cdots \\
\cdots\end{array}$ & $\begin{array}{l}\cdots \\
\cdots \\
\cdots\end{array}$ & $\begin{array}{l}\cdots \\
\cdots \\
\cdots\end{array}$ & $\begin{array}{c}25(27) \\
47(51) \\
6(6) \\
15(16)\end{array}$ & $\begin{aligned} 9 & (25) \\
18 & (50) \\
2 & (6) \\
7 & (19)\end{aligned}$ & $\begin{array}{c}16(26) \\
28(45) \\
4(6) \\
14(23)\end{array}$ & $\begin{array}{r}8(29) \\
14(50) \\
2(7) \\
4(14)\end{array}$ \\
\hline \multicolumn{5}{|c|}{ Total } & $93(100)$ & $36(100)$ & $62(100)$ & $28(100)$ \\
\hline
\end{tabular}

*Babies born with more than one type of malformation appear in one category only.

used HPT had a personal or family history of congenital malformations. None of the 55 control mothers had such a history. The difference between case and control use of HPT remains significant when these nine mothers of affected babies are excluded $\left(\gamma^{2}-9.42 ; \mathrm{P}<0.01 ; \mathrm{McNemar}^{2}\right.$ test $\left.^{2}\right)$.

Several studies have shown a possible association between the use of female sex hormones and congenital abnormalities. Gal et $a l^{3}$ were the first to report a possible association between neural tube defects and HPT. Although our results are consistent with a general teratogenic effect of HPT, they do not suggest any specific effect on the development of the neural tubes. Gal's study, however, was restricted to children with this type of abnormality. Laurence et $a l^{*}$ found no significant association between the use of oestrogens and progestogens as pregnancy tests and the birth of children with neural tube malformations. Multiple congenital malformations were described by Nora and Nora $^{5}$ in babies exposed to oestrogen-progestogen mixtures or to progestogen alone. Levy et $a l^{6}$ described congenital heart disease associated with maternal use of hormones during pregnancy, while Janerich $e t \mathrm{al}^{7}$ showed an association between exposure to exogenous sex hormones during gestation and congenital limb reduction deformities. Heinonen et $a l^{*}$ found associations between exposure to progestational agents and oestrogens and cardiovascular abnormalities; Janerich et $a l^{9}$ also showed an association between congenital heart disease and exposure to exogenous sex hormones.

Milkovich and van den Berg, ${ }^{10}$ Saxén, ${ }^{11}$ and Safra and Oakley ${ }^{12}$ suggested a possible link between benzodiazepines and congenital abnormalities. Hartz et $a l^{13}$ did not confirm this. Heinonen $e t a l^{8}$ found no statistically significant evidence that benzodiazepines were teratogenic. In the present study the number of patients exposed to these drugs was small, with no significant difference between case and control usage.

The relation between congenital abnormalities and barbiturates used in the treatment of epilepsy has been extensively documented. Since a high proportion of patients with epilepsy received anticonvulsant treatment the effect of the disease cannot be distinguished from that of the drugs used in its control. Table IV shows a significant excess of barbiturate use among cases, mainly accounted for by the use of phenobarbitone by epileptic mothers of affected babies (see table VI). Shapiro et $a l^{14}$ suggested that the rates of malformations in children of parents with epilepsy are not materially affected by the choice of maternal anticonvulsant treatment.

The excess use of HPT by case mothers found by us was not great and the association with malformations nonspecific; alternative risk-free methods of pregnancy diagnosis are, however, available and the use of HPTs is unnecessary.

Except for the risks associated with HPT we found no evidence that any of the drugs studied is a teratogen. Nevertheless, the benefits of drug treatment in the first trimester should continue to be carefully weighed against the existence of possible but hitherto undetected hazards. Weak teratogenic activity of a drug not commonly used would not have been detected by this study. We intend to undertake further studies, with increased numbers, so that small risks may be detected and newly marketed or rarely used drugs may be monitored for teratogenic effects.

We thank Professor Sir Richard Doll, Professor Sir Austin BradfordHill, Professor D J Finney, and Professor Sir Eric Scowen for their criticism and help; the staff of the area health authorities, all participating doctors, and the CSM field workers for aid in collecting data $\mathrm{Mr} \mathrm{J}$ Fisher and the staff of the medical statistics unit (OPCS) for help in analysing the data; and Miss A Dane and Mrs A Renauld for secretarial assistance.

\section{References}

${ }^{1}$ Greenberg, G, et al, British Medical Fournal, 1975, 2, 191.

2 McNemar, Q, Psychometrika, 1947, 12, 153.

${ }^{3}$ Gal, I, Kirman, B, and Stern, J, Nature, 1967, 216, 83.

${ }^{4}$ Laurence, M, et al, Nature, 1971, 233, 495.

${ }^{5}$ Nora, J J, and Nora, A H, Lancet, 1973, 1, 941.

${ }^{6}$ Levy, E P, Cohen, A, and Fraser, F C, Lancet, 1973, 1, 611.

${ }^{7}$ Janerich, D T, Piper, J M, and Glebatis, D M, New England fournal of Medicine, 1974, 291, 697.

${ }^{8}$ Heinonen, O P, Slone, D, and Shapiro, S, Birth Defects and Drugs in Pregnancy. Littleton, Massachusetts, Publishing Sciences Group, Inc, 1977.

${ }^{9}$ Janerich, D T, et al, British Medical fournal, 1977, 1, 1058

10 Milkovich, L, and van den Berg, B J, New England fournal of Medicine, 1974, 291, 1268

${ }^{11}$ Saxén, I, International fournal of Epidemiology, 1975, 4, 37.

${ }_{12}$ Safra, M J, and Oakley, G P, Lancet, 1975, 2, 478.

${ }^{13} \mathrm{Hartz}, \mathrm{S}$ C, et al, New England fournal of Medicine, 1975, 292, 726.

${ }^{14}$ Shapiro, S, et al, Lancet, 1976, 1, 272.

(Accepted 26 fuly 1977) 